\title{
Kronik Solunum Yolu Hastalıkları ve Sağlık Harcamaları: Panel Regresyon Analizi
}

\section{Chronic Respiratory Diseases and Health Expenditure: Panel Regression Analysis}

\author{
Canser Boz $*^{1}$, Haluk Zülfikar ${ }^{2}$
}

\begin{abstract}
Introduction: The aim of this study is to examine the effect of chronic respiratory diseases, which is one of the noncommunicable diseases, on health expenditures using the static panel regression method. Methods: The static panel data methodology was used in the study. The data set consists of annual data from 36 OECD countries covering the period 20042017. STATA 13.0 program was used for analysis. Results: It was concluded that the logarithm of the prevalence of chronic respiratory diseases has an econometrically significant and positive effect on the logarithm of the total amount of health expenditure per capita by purchasing power parity, on the logarithm of the total amount of public health expenditure per capita, and on the logarithm of total OOP spending per capita. Conclusion: Chronic respiratory diseases, which are among noncommunicable diseases, pose financial risks in both developed and developing countries and threaten the financial continuity and effectiveness of health systems.
\end{abstract}

Key words: Health expenditures, noncommunicable diseases, panel data, health economics

\section{ÖZET}

Giriş: Bu çalışmanın amacı, bulaşıcı olmayan hastalıklardan kronik solunum yolu hastalıklarının sağlık harcamaları üzerindeki etkisini statik panel regresyon yöntemi ile incelemektir. Yöntem: Çalışmada, statik panel veri metodolojisi kullanılmıştır. Veri seti 36 (Organisation for Economic Co-operation and Development) OECD ülkesine ait 2004-2017 dönemini kapsayan yıllık verilerden oluşmaktadır. Analizler için STATA 13,0 programı kullanılmıştır. Bulgular: Kronik solunum yolu hastalıklarının prevalansının logaritmasının, satın alma gücü paritesine göre kişi başı toplam sağlı harcaması miktarının logaritması üzerinde, kişi başı toplam kamu sağlık harcaması miktarının logaritması, ve kişi başı toplam cepten sağlık harcamasının logaritması üzerinde ekonometrik olarak anlamlı ve pozitif etkisinin olduğu sonucuna ulaşılmıştır. Sonuç: Bulaşıcı olmayan hastalıklar içinde yer alan kronik solunum yolu hastalıkları, gerek gelişmiş, gerekse de gelişmekte olan ülkelerde mali açıdan risk oluşturmakta ve sağlık sistemlerinin finansal açıdan devamlılığını ve etkinliğini tehdit etmektedirler

Anahtar kelimeler: Sağlık harcamaları, bulaşıcı olmayan hastalıklar, panel veri, sağlık ekonomisi

Received / Geliş tarihi: 22.02.2021, Accepted / Kabul tarihi: 18.09.2021

${ }^{1}$ Istanbul University- Cerrahpasa, Health Sciences Faculty, Health Management Department-Health Economics, ISTANBUL (ORCID: 00000002-6136-4479)

${ }^{2}$ Istanbul University, Faculty of Economics, Economics, İSTANBUL (ORCID: 0000-0002-9712-5373)

*Address for Correspondence / Yazışma Adresi: Istanbul University- Cerrahpasa, Health Sciences Faculty Hadımköy/Istanbul-TÜRKIYE,

E-mail: canser.boz@istanbul.edu.tr

Tel: +90 5067761587

Boz C, Zülfikar H. Kronik Solunum Yolu Hastalıkları ve Sağlık Harcamaları: Panel Regresyon Analizi. TJFMPC, 2021;15(4): 818-827.

DOI: $10.21763 /$ tjfmpc.883176 


\section{Gİiș}

Bulaşıcı olmayan hastalıklar (BOH), insanları yaşamı boyunca etkileyen, beşeri, ekonomik, sosyal açıdan birçok olumsuz etkisi olan uzun dönemli ve maliyetli bakım gerektiren kronik hastalıklar olarak isimlendirilmektedir. ${ }^{1}$ Dünya Sağlık Örgütü (DSÖ) ve Birleşmiş Milletler (BM) tarafından bulaşıcı olmayan hastalıklar, 21. yüzyılın en önemli sağlık sorunlarından birisi olarak tanımlanmaktadır.

Bireysel yaşam tarzındaki değişiklikler, çevresel faktörlerin etkisi, yaşlanma, beslenme alışkanlıklarının değişmesi, yaşam süresinin uzaması gibi nedenlerle kanser, diyabet, kronik solunum yolu hastalıkları, koroner kalp hastalığı gibi bulaşıcı olmayan hastalıklar son yıllarda dünya genelinde ölümlerin ve engelliliklerinin temel sebepleri arasına girmiş durumdadır. ${ }^{2}$ Dünya genelindeki toplam ölümlerin yaklaşık $\% 65,5$ 'i, (3) ve Türkiye'de 30-70 yaş ölümlerin yaklaşık \%87'si (4) bulaşıcı olmayan hastalıklardan kaynaklanmaktadır. Bulaşıcı olmayan hastalıklar içinde dağılıma bakıldığında ise, bu hastalıklara bağlı ölümlerin yıllık \%46,2'si kalp ve damar hastalıklarına, yüzde 21,7'si kanserlere, yüzde 10,7 'si astım ve kronik obstrüktif akciğer hastalıklarını içeren kronik hava yolu hastalıklarına, yüzde 4'ü diyabete bağlıdır. ${ }^{(5)}$ Bulaşıcı olmayan hastalıkların, toplumda yaygınlaşması ve artmasının beşeri, sosyal ve ekonomik alanlarda önemi negatif dışsallıklarının olduğu bilinmekte; bu hastalıkların, iktisadi üretkenliği azaltıp ve ekonomik yoksulluğu artırmakta rol oynadığı kabul edilmektedir. Teorik olarak bakıldığında, sağlık düzeyinin kötü olması bir diğer ifade ile hastalıkların artması yalnızca emek arzı ve verimliliğini azaltmak ile kalmamakta aynı zamanda beşeri sermaye birimini de olumsuz etkilemektedir. $\mathrm{Bu}$ nedenle hastalıklar bireylerin kişisel ve sosyal refahlarını olumsuz etkilemekle birlikte, aynı zamanda üretim fonksiyonu aracılığıyla makroekonomik açıdan ekonomik büyüme ve gelir düzeyini de olumsuz etkilemektedir. ${ }^{(6)}$

Hastalıklar, beşeri sermaye stokunu ve emek verimliliğini azaltarak önemli oranda gelir ve çıktı kaybına sebep olmaktadır. ${ }^{(7)}$ Gelir ve çıktı kaybının yanı sıra hastalıklar aynı zamanda sağlık harcamalarını da arttırıcı bir etkiye sahiptir. Bulaşıcı olmayan kronik hastalıklarda ise bu etki daha yüksek olmaktadır. Çünkü bulaşıcı olmayan hastalıklar uzun dönemli, sürekli bakım gerektiren karmaşık vakalardır. Bu noktadan hareket ile bu çalışmada kronik solunum yolu hastalıklarının sağlık harcamaları üzerindeki etkisine odaklanılmıştır.

Bulaşıcı olmayan hastalıklar, halen dünya çapındaki ölüm ve hastalıkların önde gelen sebepleri olduğundan, dünya çapındaki en önemli sağlık problemlerinden biridir. $\mathrm{Bu}$ hastalıklar dünya üzerindeki en büyük katiller arasında nitelendirilir. BOH'lara bağlı birçok ölüm, tütün kullanımı, sağlıksız diyet, fiziksel inaktivite ve alkolün zararlı kullanımını içeren risk faktörleri hedeflenerek engellenebilir. $\mathrm{Bu}$ nedenle bulaşıcı olmayan hastalıkların en önemli risk faktörleri, tütün kullanımı, sağlıksız ve dengesiz beslenme, yetersiz fiziksel aktivite ve alkol kullanımı olarak siralanmaktadır. ${ }^{(8)}$

2017 yılında bulaşıcı olmayan hastalıklar, dünya genelinde 70 yaş altına ölüm oranları açısından en yüksek paya sahip hastalık grubu olarak gerçekleşmiştir. Bulaşıcı olmayan hastalıklar, üç hastalık grubu içinde- bulaşıcı hastalıklar, bulaşıcı olmayan hastalıklar ve dişsal yaralanmalar- \%52 oran ile ilk sıradadır. Bulaşıcı olmayan hastalıkların, kendi içerisinde ölüm oranı açısından dağılımına bakıldığında ise en yüksek payın \%37 ile dolaşım sistemi hastalıkları olduğu görülmektedir. Bundan sonra, 70 yaş altında en yüksek ölüm oranına sahip hastallk \%27 ile kanserler, \%8 ile solunum yolu hastalıkları olarak sıralanmıştır. Bulaşıcı olmayan hastalıkların mortalite etkileri ile birlikte, dünya çapında bu hastalıkların morbidite etkisi de vardır. Örneğin, bulaşıcı olmayan hastalıklar dünya çapında kaybedilen sağlıklı yaşam yıllarının yüzde 62 'sini oluşturmaktadır. Öte yandan, bulaşıcı olmayan hastalıklar düşük ve orta gelirli ülkelerde ciddi morbiditeye neden olur ve düşük gelirli ülkelerde (DisabilityAdjusted Life. Years) DALY'lerin üçte birini ve orta gelirli ülkelerde yaklaşık üçte ikisini oluşturmaktadır. BOH ile ilişkili morbiditenin en düşük olduğu Afrika da bile bu hastalıklar toplam DALY'nin yüzde 21 'ini oluşturmaktadır. ${ }^{(8)}$

Küresel düzeyde, 2017 yılında, hastalık yükünün yüzde 60'ından fazlası bulaşıcı olmayan hastalıklardan (NCDs) kaynaklanmaktadır. Bu oran anne, yenidoğan ve beslenme hastalıklarından kaynaklı hastalıklar için yüzde 28, yaralanmalardan kaynaklı olarak ise yüzde 10 civarındadır. Dahası, Engelliliğe Uyarlım Yaşam Yılı (DALY) olarak ölçülen DALY yüküne göre bulaşıcı olmayan hastalıkların payı 1990'lardan beri artmaktadır. 2017 yılında, yıllık hastalık yükü içindeki bulaşıcı olmayan hastalıkların oranı\% 62,05 iken, 1990'da toplam hastalık yükü içindeki bulaşıcı olmayan hastalıkların oranı 43,22\% olarak ölçülmüştür. ${ }^{(8)}$

Gerek mortalite üzerindeki etkisi, gerekse de morbidite içindeki payı açısından sağlık sistemi üzerinde risk oluşturan bulaşıcı olmayan hastalıkların, sosyal ve ekonomik etkisine yönelik çalışmaların önemi son dönemde artmaya başlamıştır. Bu çalışmada da, bulaşıcı olmayan hastalıklardan kronik solunum yolu hastalıklarının sağlık harcamaları üzerindeki etkisi statik panel regresyon metodu ile incelenmiştir. 


\section{YÖNTEM}

Panel veri analizi, temelde yatay kesit veri ve zaman serisi analizinin bir araya getirilmiş halidir. Bu nedenle panel veri modellerinde hem zaman, hem de yatay kesit bir diğer ifade ile birim boyutu bir arada bulunmaktadır. Ancak panel veri modellerinin analizinde, genellikle yatay kesitler arası değişim veya heterojenliğe odaklanır.(9) Gözlem sayısının fazla olması, serbestlik derecesinin artması, çoklu doğrusal bağlantı probleminin azalması, kesit veri ya da zaman serisi verisi modellerinden daha kapsamlı modeller kurulabilmesi, birim değişkenliğinin ve gözlenemeyen heterojenliğin modele dâhil edebilmesi, tahmin sapmasının azalması gibi nedenler panel veri ile çalışmanın araştırmacılara sağladığı avantajlar arasında sıralanmaktadır. ${ }^{(10)}$

En genel hali ile panel veri modelli aşağıdaki gibi gösterilmektedir.

$$
\begin{gathered}
Y_{i t}=\beta_{0 i t}+\beta_{1 i t} X_{1 i t}+\beta_{2 i t} X_{2 i t}+\cdots+\beta_{k i t} X_{k i t}+ \\
u_{i t} \mathrm{i}=1 \ldots \ldots \mathrm{N}, \mathrm{t}=1 \ldots \ldots \mathrm{T}
\end{gathered}
$$

Panel veri modellerinde, sabit ve eğim parametresinin heterojenliklerine göre 5 durum söz konusu olabilir. Bunlar;

Panel verilerle çalışırken, sabit ve eğim parametrelerinin birimlere ve zamana göre değişmediği klasik model,

$$
\begin{gathered}
Y_{i t}=\beta_{0}+\beta_{1} X_{1 i t}+\beta_{2} X_{2 i t}+\cdots+\beta_{k} X_{k i t}+ \\
u_{i t} \mathrm{i}=1 \ldots \ldots \mathrm{N}, \mathrm{t}=1 \ldots \ldots \mathrm{T}(1)
\end{gathered}
$$

Sabit parametrenin sadece birimlere göre değiştiği, eğim parametrelerinin ise değişmediği, ya da sabit parametrenin sadece zamana göre değiştiği eğim parametrelerinin ise değişmediği, sabit parametresi heterojen tek yönlü model,

$$
\begin{gathered}
Y_{i t}=\beta_{0 i}+\beta_{1} X_{1 i t}+\beta_{2} X_{2 i t}+\cdots+\beta_{k} X_{k i t}+ \\
u_{i t} \mathrm{i}=1 \ldots \ldots \mathrm{N}, \mathrm{t}=1 \ldots \ldots \mathrm{T}(2 \mathrm{a}) \\
Y_{i t}=\beta_{0 t}+\beta_{1} X_{1 i t}+\beta_{2} X_{2 i t}+\cdots+\beta_{k} X_{k i t}+ \\
u_{i t} \mathrm{i}=1 \ldots \ldots \mathrm{N}, \mathrm{t}=1 \ldots \ldots \mathrm{T}(2 \mathrm{~b})
\end{gathered}
$$

Sabit parametrenin hem birimlere, hem de zamana göre değiştiği eğim parametrelerinin ise değişmediği, sabit parametresi heterojen iki yönlü model,

$$
\begin{gathered}
Y_{i t}=\beta_{0 i t}+\beta_{1} X_{1 i t}+\beta_{2} X_{2 i t}+\cdots+\beta_{k} X_{k i t}+ \\
u_{i t} \mathrm{i}=1 \ldots \ldots \mathrm{N}, \mathrm{t}=1 \ldots \ldots \mathrm{T}(3)
\end{gathered}
$$

Hem sabit, hem de eğim parametrelerinin sadece birimlere göre değiştiği, sabit ve eğim parametresi heterojen tek yönlü model,

$$
\begin{gathered}
Y_{i t}=\beta_{0 i}+\beta_{1 i} X_{1 i t}+\beta_{2 i} X_{2 i t}+\cdots+\beta_{k i} X_{k i t}+ \\
u_{i t} \mathrm{i}=1 \ldots \ldots \mathrm{N}, \mathrm{t}=1 \ldots \ldots \mathrm{T}(4)
\end{gathered}
$$

Hem sabit, hem de eğim parametrelerinin hem birimlere hem de zamana göre değiştiği, sabit ve eğim parametresi heterojen iki yönlü model,

$$
\begin{gathered}
Y_{i t}=\beta_{0 i t}+\beta_{1 i t} X_{1 i t}+\beta_{2 i t} X_{2 i t}+\cdots+\beta_{k i t} X_{k i t}+ \\
u_{i t} \mathrm{i}=1 \ldots \ldots \mathrm{N}, \mathrm{t}=1 \ldots \ldots \mathrm{T}(5)
\end{gathered}
$$

Panel veri analizinin kullanım amacı, kesite ait etkilerin varlığı altında tutarlı tahminler elde edebilmektir. Kesite özgü olan bu etkiler genelde zamanla farklılaşmayan ve gözlenemeyen değişkenlerdir. ${ }^{(11)} \mathrm{Bu}$ nedenle, literatürde en sıklıkla kullanılan panel veri modelleri $2 \mathrm{a}$ ve 4 numaralı panel modelleridir. Panel veri modellerinde " $u_{i t}$ " ile ifade edilen terim, hata terimini temsil etmektedir ve hata teriminin içerisinde gözlenemeyen etkiler bulunmaktadır. Çalıșmamızda da, kronik solunum yolu hastalıklarının sağlık harcamaları üzerindeki etkisi sabit parametresi heterojen tek yönlü model olan 2a modeli ile incelenmiştir.

Kronik solunum yolu hastalıklarının, sağlık harcamaları üzerindeki etkisini ampirik olarak incelemek için 2011 yılında Xu ve arkadaşları tarafından geliştirilen sağlık harcamalarının belirleyicileri modelinden yararlanılmıştır. Modele göre, bir ülkedeki sağlık harcamaları, gelir, toplumun yapısı (yaşlılık oranı, eğitim vs), sağlık teknolojilerinin gelişimi, sağlık sisteminin karaktetristik özellikleri, toplum hastalık paterni gibi faktörlere bağlanmıştır. ${ }^{(12)}$

Literatürde, sağlık harcamalarının belirleyicilerine yönelik olarak farklı yöntemlerde farklı çalışmalar mevcuttur. Bazı çalışmalar mikro veriler üzerinden kurulan modelleri içermekte iken, bazı çalışmalar ise makroekonomik veriler yardımı ile kurulan ekonometrik modellere dayanmaktadır. ${ }^{(12)}$ Yapılan çalışmalarda gelir, toplam sağlık harcamalarının seviyesi ve büyüme hızındaki ülkeler arasındaki farklılıkları açıklamada çok önemli bir faktör olarak tanımlanmaktadır. Örneğin, Newhouse, Gerdtham ve Jonsson, HitirisandPosnett yapmış oldukları çalışmalarında, gelir düzeyini sağlık harcamalarını etkileyen en önemli faktörlerden biri olarak bulmuşlardır. ${ }^{(13-14-}$ ${ }^{15)}$ Getzen, yapmış olduğu çalışmasında gelirdeki artışın 3 ile 5 yıl içinde sağlık harcamalarını arttırıcı yönde etkisi olacağ 1 ifade etmiştir. ${ }^{(16)}$ Baltagi ve Moscone ise, 1971-2004 döneminde 20 OECD ülkesinde sağlık harcamaları ile gelir arasındaki ilişkiyi uzun dönemli olarak incelemişlerdir. Yaptıkları analiz sonucunda, sağlık harcamalarının ve belirleyicilerinin çoğunun durağan olmadığını ve uzun dönemde sağlık harcamaları ile gelir düzeyinin ilişkili olduğunu bulmuşlardır. ${ }^{(17)}$

Literatürde, sağlık harcamaları üzerinde etkisi incelenen faktörlerden bir diğeri ise eğitim seviyesidir. Eğitim, sağlık hizmetlerine olan talebi ve bu nedenle sağlı harcamalarını etkileyen bir diğer önemli değişkendir. Eğitim seviyesi daha yüksek olanlar, eğitim seviyesi daha düşük olanlara göre sağlık bilinçleri nedeniyle sağlık hizmetlerini daha fazla kullanma eğilimindedirler. Bu nedenlere bağlı olarak da sağlık harcamaları 
artmaktadır. ${ }^{(12)}$ Ancak diğer taraftan eğitim düzeyi yüksek olan kişilerin, sağlık bilinç düzeylerinin artması, sağlık okuryazarlıklarının gelişmesi ve hijyen kurallarına uyma gibi nedenlerle sağlık durumlarının görece olarak daha iyi olacağı ve koruyucu yöntemeler sayesinde sağlık talebinin etkileneceği ve dolayısıyla da sağlık harcamalarının azalacağı yönünde görüşler de mevcuttur. ${ }^{(18)}$

Sağlık harcamalarının bir diğer önemli belirleyicisi ise toplumun yapısıdır. Küresel boyutta modern toplumların hızla yaşlanan nüfuslarla karşı karşıya kalmasıyla, nüfusların yaşlanması toplum yapısında 21. yüzyılda ortaya çıkan önemli değişikliklerden biridir. ${ }^{(19)} \mathrm{Genel}$ olarak genç toplumlarda, hastalıkların daha nadir olması, sağlık bakım ihtiyacının azalması, sağlık hizmeti kullanımının daha düşük olması gibi nedenlerle görece olarak daha yaşlı toplumlara göre sağlık harcamasının daha düşük olması beklenmektedir. Japonya'da yapılan bir çalışmada, yaşlıların gençlere göre sağlık hizmetlerini 3,2 kez yıllık daha fazla kullandıkları bu nedenle sağlık harcamalarının yükseldiği bulunmuştur. ${ }^{(20)}$ Ekonomik İşbirliği ve Kalkınma Örgütü (OECD) tarafından yayınlanan rapora göre ise, gelişmiş ülkelerde yaşlı nüfus için kişi başına düşen sağlık harcamalarının maliyeti, 65 yaş altındaki bireyler için yapılan maliyete göre daha yüksek hızda son yıllarda artmıştır. ${ }^{(21)}$

$\mathrm{Xu}$ ve arkadaşlarına göre, sağlık harcamalarının belirleyicilerinden bir diğeri ise sağlık sisteminin karakterikstik yapısıdır. Sağlık sisteminin karakteristik yapısı ise hizmet sunumu, hizmet finansmanı, dış destekler ve ödeme mekanizmaları gibi faktörlerden oluşmaktdır. ${ }^{(12)}$ Örneğin zevk zincirinin olduğu ve birinci basamak sağlık hizmetlerinin yoğun kullanıldığı (kapı tutucu özellik taşıması) ülkelerde sağlık harcamaları düşme eğilimdedir. ${ }^{(14)}$ Sağlık sisteminin vergiler, sosyal sigorta primleri, cepten ödemeler temelli olarak finanse edildiği durumlara göre de sağlık harcamalarının düzeyi değişmektedir. Örneğin OECD ülkelerinde yapılmış bir çalışmada, sosyal sağlık sigortası mekanizmasının bulunduğu ülkelerde kişi başına sağlık harcamasının daha yüksek olduğu bulunmuştur. D1ş desteklerin miktarı ve yoğunluğu da, özellikle gelişmekte olan ülkelerde sağlık harcamalarının düzeyini etkilemektedir. Örneğin Gaag ve Stimac yaptıkları çalışmada, sağlığa özgü resmi kalkınma yardımının toplam sağlık harcamaları üzerinde önemli bir etkisi olmamasına rağmen, kamu harcamaları üzerinde 0,138 esnekliğe sahip olduğunu bulmuşlardır. Ayrıca bireysel ve kurumsal sağlık hizmet sunucularına ödeme mekanizmaları da sağlık harcamalarını etkilemektedir. ${ }^{(12)}$

$\begin{array}{cccc}\text { Sağlık } & \text { harcamalarının } & \text { belirleyicileri } \\ \text { üzerine } & \text { literatür } & \text { incelendiğinde } & \text { etkisi olduğu }\end{array}$ bilinmek ile birlikte, ampirik olarak çok fazla incelenmeyen bir diğer faktör ise toplumun hastalık yapısı ya da hastalıkların toplumda görülme hızıdır. Literatürde yapılan çalışmalara bakıldığında son yıllarda artan bulaşıcı olmayan hastalıkların, daha yüksek sağlık harcamasına neden olduğu şekinde bir kanı vardır. Örneğin Vandenberghe ve Albrecht tarafindan 2019 yılında yapılan bir sistematik derlemede, bulaşıcı olmayan hastalıkların hem sağlık harcamalarının artmasına, hem de ekonomik çıktının azalmasına neden olduğu şeklinde bir sonuca ulaşılmıştır. Liu ve arkadaşları tarafından yapılan bir başka çalışmaya göre ise, koroner kalp hastalığının 1999'da İngiltere'de maliyeti 1,73 milyar sterlin olduğu bulunmuştur. Schmid ise, Almanya'da kardiyovasküler hastalıkların tedavi edilmesinin doğrudan tıbbi maliyetlerini hesaplamış ve bu hastalıkların Alman sağlık sistemi üzerinde yüksek mali etkiye neden olduğu sonucuna ulaşılmıştır. ${ }^{(22-23-24)}$ Bulaşıcı olmayan hastalıklarda, sağlık harcaması etkisi daha yüksek olmaktadır. Bu durumun nedeni genellikle bulaşıcı olmayan hastalıkların, uzun dönemli bakım gerektirmesi, kullanılan sağlık teknolojisi yoğunluğunun yüksek olmas1, yoğun emek ve bilgi gerektirmesi, sürekli bakım ihtiyacı ve genellikle hastalıkların yaşam boyu devam etmesi olarak siralanabilmektedir.

Çalışmada, kronik solunum yolu hastalıklarının sağlık harcamaları üzerindeki etkisi üç farklı sağlık harcaması değişkeni üzerinden incelenmiştir. Bunlar satın alma gücü paritesine göre hesaplanmış toplam kişi başı sağlık harcaması, toplam kişi başı kamu sağlık harcaması ve toplam kişi başı cepten yapılan sağlık harcamalarıdır. Kurulan modelin amprik analizinde veriler; Dünya Bankas1, Global Health Data Exchange-GHDx veri taban1, International Monetary Fund ve UNESCO Institute for Statistics (2019) veri tabanından elde edilmiştir. Analizde örneklem OECD ülkeleri olarak belirlenmiştir. 36 OECD ülkesi için 2004-2017 dönemini kapsayan analizler yapılmıştır. Bu dönem aralığının kullanılmasının nedeni, modelde dengesiz panel ile çalışmamaktır. Örnekleme dâhil olan ülkeler aşağıda Tablo I'de sunulmuştur.

Hastalıkların, sağlık harcamaları üzerindeki etkisi üç farklı sağlık harcaması göstergesi için ayrı ayrı inceleneceğinden bağımlı değişken her üç hastalık grubu için de toplam kişi başına düşen sağlık harcaması, toplam kişi başına düşen kamu sağlık harcaması ve toplam kişi başına düşen cepten sağlık harcaması olacaktır.

Analizde yer alan ilk bağımlı değişken olan "satın alma gücü paritesine göre hesaplanmış kişi başına düşen sağlık harcaması tutarı değişkenidir. $\mathrm{Bu}$ değişken, Dünya Bankası veri tabanından elde edilmiştir. Analizde "kbsh" olarak gösterilmektedir. Logaritmik formda kullanılacaktır. $\mathrm{Bu}$ nedenle "lkbsh" olarak kodlanmıştır. Bağımlı değişkenin kişi 
başına düşen toplam sağlık harcaması olduğu modeller "1" numaralı sağlık harcaması modeli olarak adlandırılacaktır.

Analizde yer alan ikinci bağımlı değişken olan satın alma gücü paritesine göre hesaplanmış kişi başına düşen sağlık kamu harcaması tutarı değişkenidir. $\mathrm{Bu}$ değişken dünya bankası veri tabanından elde edilmiştir. Analizde "gov" olarak gösterilmektedir. Logaritmik formda kullanılacaktır. $\mathrm{Bu}$ nedenle "lgov" olarak kodlanmıştır. Bağımlı değişkenin kişi başına düşen toplam kamu sağlık harcaması olduğu modeller "2" numaralı sağlık harcaması modeli olarak adlandırılacaktır.

Analizde yer alan üçüncü bağımlı değişken olan kişi başına düşen toplam cepten sağlık harcaması tutarı değişkenidir. Bu değişken de Dünya Bankası veri tabanından elde edilmiştir. Analizde "oop" olarak gösterilmektedir. Logaritmik formda kullanılacaktır. $\mathrm{Bu}$ nedenle "loop" olarak kodlanmıştır. Bağımlı değişkenin kişi başına düşen toplam cepten sağlık harcaması olduğu modeller " 3 " numaralı sağlık harcaması modeli olarak adlandirılacaktır.

Kronik solunum yolu hastalıklarının, sağlık harcaması üzerindeki etkilerini ölçebilmek için modele bu hastalıkların proxy göstergesi olarak 100.000 kişi başına düşen prevelans değeri alınmıştır. Modelde, kronik solunum yolu hastalıklarının (crd) prevelans değeri Global Health Data Exchange-GHDx veri tabanından elde edilmiştir. Bu veri ilgili yılda toplumda 100.000 kişi başına düşen toplam vaka sayısıdır. Logaritmik formda kullanılacaktır. Analizde "lcrd" olarak isimlendirilmiştir.

Analizde yer alan bir diğer sağlık harcaması belirleyicisi değişkeni ise gelir düzeyidir. Gelir değişkeni Satın Alma Gücü (SAG-PPP) paritesine göre hesaplanan kişi başı reel Gayri Safi Yurt İçi Hâsıla olarak modele dahil edilmiştir. Bu değişken, Dünya Bankası veri tabanından elde edilmiştir. Analizde "income" olarak gösterilmektedir. Sağlık harcamalarının bir diğer belirleyicisi ise eğitim düzeyidir. Eğitim değişkeninin proxy göstergesi olarak beklenen eğitim yılı (yıl) kullanılmıştır. Bu veri UNESCO Institute for Statistics (2019) veri tabanından elde edilmiştir. Analizde bu değişken "edu" olarak gösterilmiştir. Modelde, sağlık sisteminin yapısının temsilen modele toplam sağlık harcamaları içinde kamunun payı değişkeni eklenmiştir. Bu sayede finansmanın kamu ya da özel ağırlıklı olmasının etkisi gözlemlenecektir. Bu veri, Dünya Bankası veri tabanından elde edilmiştir. Analizde bu değişken "ss" olarak gösterilmiştir. Literatürde yapılan çalışmalarda, nüfus yaşı yapısı ve yaşlanmanın sağlık harcamalarını arttırdığı şeklinde bulgular vardır. Makro düzeyde toplumun yaşlanma seviyesinin ölçütlerinden birisi ise topla nüfus içinde +65 yaş üzeri bireylerin oranıdır. Modelde de toplumun yaşlanmasının proxy göstergesi olarak +65 yaş üzeri nüfusun toplam nüfus içindeki oranı kullanılmıştır. Bu veri, Dünya Bankası (2020) veri tabanından elde edilmiştir. Analizde bu değişken "age" olarak gösterilmiştir. Tüm ekonometrik analizler STATA 13 programında gerçekleştirilmiştir.

\section{BULGULAR}

Statik panel veri metodolojisi kullanarak, 36 OECD ülkesinde 2004-2017 y1lları arasında kronik solunum yolu hastalıklarının prevelansının sağlık harcamaları üzerindeki etkisi Xu ve arkadaşlarının (2011) modeli genişletilerek sabit etkiler panel regresyon yöntemi kullanılarak tahmin edilmiştir. Tahmin yöntemi olarak, sabit etkiler modelinin kullanılmasının nedeni test sonuçlarıdır.

Kronik solunum yolu hastalıklarının, sağlık harcamaları üzerindeki etkilerini incelemek amacıyla oluşturulan modellere ait denklemler şu şekildedir;

$$
\begin{aligned}
& l k b s h_{i t}=\AA_{0}+\AA_{1} l c r d_{i t}+ \\
& \AA_{2} \text { income }_{i t}+\AA_{4} \text { age } i t+\AA_{5} s s_{i t}+\AA_{6} e d u_{i t}+ \\
& u_{1 i t}(1) \\
& \operatorname{lgov}_{i t}=\overline{\mathrm{W}}_{0}+\overline{\mathrm{W}}_{1} l_{c r d}+ \\
& \overline{\mathrm{W}}_{2} \text { income }_{i t}+\overline{\mathrm{W}}_{4} \text { age } \text { it }_{i t}+\overline{\mathrm{W}}_{5} s s_{i t}+\widetilde{\mathrm{U}}_{6} e d u_{i t}+ \\
& u_{2 i t}(2) \\
& \text { loop }_{i t}=\mathrm{b}_{0}+\mathrm{b}_{1} \text { lcrd }_{i t}+\mathrm{b}_{2} \text { income }_{i t}+\mathrm{b}_{4} \text { age } \text { it }+ \\
& \mathrm{b}_{5} s_{i t}+\mathrm{b}_{6} e d u_{i t}+u_{3 i t}(3)
\end{aligned}
$$

- $\quad$ kbsh: satın alma gücü paritesine göre hesaplanmış kişi başı toplam sağlık harcamas1, dolar cinsinden,

- gov: satın alma gücü paritesine göre hesaplanmış kişi başı toplam kamu sağlık harcamas1, dolar cinsinden,

- $\quad$ oop: satın alma gücü paritesine göre hesaplanmış kişi başı toplam cepten sağlık harcaması, dolar cinsinden

- income: satın alma gücü paritesine göre toplam kişi başı gayri safi yurt içi hasıla tutar1, dolar cinsinden

- $\quad$ age: +65 yaş üzeri nüfusun toplam nüfus içindeki payı

- $\quad$ ss: toplam sağlık harcaması içindeki kamu sağlık harcamalarının oranı

- $\quad$ edu: beklenen okullaşma yılı

- $\quad \mathrm{u}$ : hata terimi, i: OECD ülkeri, t: yılar 
Tablo 1. Örnekleme Dahil Olan Ülkeler

\begin{tabular}{|c|c|c|}
\hline \multicolumn{3}{|c|}{ OECD Ülkeleri } \\
\hline $\begin{array}{l}\text { Amerika } \\
\text { Birleşik } \\
\text { Devletleri }\end{array}$ & İrlanda & Lüksemburg \\
\hline Almanya & İspanya & Macaristan \\
\hline Avustralya & İsrail & Meksika \\
\hline Avusturya & İsveç & Norveç \\
\hline Belçika & İsviçre & Polonya \\
\hline Çekya & İtalya & Portekiz \\
\hline Danimarka & İzlanda & Slovak \\
\hline Estonya & Japonya & Slovenya \\
\hline Finlandiya & Kanada & Şili \\
\hline Fransa & Kore & Türkiye \\
\hline Hollanda & Letonya & Yeni Zelanda \\
\hline İngiltere & Litvanya & Yunanistan. \\
\hline
\end{tabular}

Tablo 2. F Testi Birim Etkisi Sınaması- Kronik Solunum Yolu Hastalıkları

\begin{tabular}{|l|l|l|l|l|l|}
\hline \multicolumn{2}{|l|}{ Model 1 } & \multicolumn{2}{l|}{ Model 2 } & \multicolumn{2}{l|}{ Model 3 } \\
\hline $\mathrm{F}(35,463)$ & $102,71 * * *$ & $\mathrm{~F}(35,463)$ & $129,47 * * *$ & $\mathrm{~F}(35,463)$ & $55,73 * * *$ \\
\hline $\mathrm{p}$ & 0,000 & $\mathrm{p}$ & 0,000 & $\mathrm{p}$ & 0,000 \\
\hline
\end{tabular}

*** 0,05 düzeyinde anlamlıdır.

Sabit etkiler modeli tahmin sonuçlarına geçmeden önce, 1,2 ve 3 numaralı modellerde bağımsız değişkenler arasında çoklu doğrusal bağlantı olup olmadığının sinaması gerçekleştirilmiştir. VIF (Variance Inflation Factor) çoklu doğrusal bağlantı sınamasına göre kronik solunum yolu hastalıklarının sağlık harcamaları üzerindeki etkisini inceleyen her üç modelde de yer alan bağımsız değişkenler arasında çoklu doğrusal bağlantı probleminin olmadı ğı sonucuna ulaşılmıştır. Tüm VIF değerleri çoklu doğrusal bağlantı eşik değeri olan 5'in altında bulunmuştur.

VIF sınamasından sonra, kronik solunum yolu hastalıklarının prevelansının sağlık harcamaları üzerindeki etkisi modelinde birim/zaman etkisinin olup olmadığının sınaması yapılmıştır. Yapılan $\mathrm{F}$ testi birim etki sınaması Tablo 2'deki gibidir.

Yapılan F testi birim etkisi sınamasına göre 1 numaralı model için test istatistiği 102,71 ve olasılık değeri (p) 0,000, 2 numaralı model için test istatistiği 129,47 ve olasılık değeri 0,000 ve son olarak 3 numaralı model için test istatistiği 55,73 ve olasılık değeri 0,000 olarak hesaplanmıştır. Bu sonuçlar, kronik solunum yolu hastalıklarının sağlık harcamaları üzerindeki etkisini incelemek için oluşturulan her üç modelde de birim etki olduğunu göstermektedir. Bu durumda kronik solunum yolu hastalıkları modelleri panel veri metodolojisi bölümünde açıklanan 1 numaralı panel veri modeli olan klasik model değildir. Bu nedenle hastalıkların sağlık harcamaları üzerindeki etkisini tahmin etmek için en küçük kareler tahmincisinin kullanılması uygun olmayacaktır.

Kronik solunum yolu hastalıklarının, sağllk harcamaları üzerindekisi etkisini incelemek için kurulan modellerde zaman etkisinin varlığını sınamak için yapılan $\mathrm{F}$ testi zaman etkisi sınaması Tablo 3’teki gibidir. 
Tablo 3. F Testi Zaman Etkisi Sınaması-Kronik Solunum Yolu Hastalıkları

\begin{tabular}{|l|l|l|l|l|l|}
\hline \multicolumn{2}{|l|}{ Model 1 } & \multicolumn{2}{l|}{ Model 2 } & \multicolumn{2}{l|}{ Model 3 } \\
\hline $\mathrm{F}(13,485)$ & 1,92 & $\mathrm{~F}(13,485)$ & 1,22 & $\mathrm{~F}(13,485)$ & 0,80 \\
\hline $\mathrm{p}$ & 0,105 & $\mathrm{p}$ & 0,172 & $\mathrm{p}$ & 0,356 \\
\hline
\end{tabular}

Tablo 4. Driscoll-Kraay Standart Hatalarla Tahmin Sonuçları- Kronik Solunum Yolu Hastalıkları

\begin{tabular}{|c|c|c|c|c|c|c|c|c|c|}
\hline \multicolumn{4}{|c|}{$\begin{array}{l}\text { Model 1- } \\
\text { Bağımlı Değişen: lkbsh } \\
\text { Tahmin Yöntemi: Sabit Etkiler Grup İçi } \\
\text { Tahmincisi } \\
\text { Grup Değişkeni: Ülkeler } \\
\text { R-sq: grupiçi }=0,8000 \mu \\
\text { Gözlem Sayısı:504 } \\
\text { Grup Sayısı:36 }\end{array}$} & \multicolumn{3}{|c|}{$\begin{array}{l}\text { Model 2- } \\
\text { Bağımlı Değişen: lgov } \\
\text { Tahmin Yöntemi: Sabit Etkiler } \\
\text { Grup İçi Tahmincisi } \\
\text { Grup Değişkeni: Ülkeler } \\
\text { R-sq: grupiçi }=0,8292 \mu \\
\text { Gözlem Sayısı:504 } \\
\text { Grup Sayısı:36 }\end{array}$} & \multicolumn{3}{|c|}{$\begin{array}{l}\text { Model 3- } \\
\text { Bağımlı Değişen: loop } \\
\text { Tahmin Yöntemi: Sabit Etkiler } \\
\text { Grup İçi Tahmincisi } \\
\text { Grup Değişkeni: Ülkeler } \\
\text { R-sq: grupiçi }=0,3656 \mu \\
\text { Gözlem Sayısı:504 } \\
\text { Grup Sayısı:36 }\end{array}$} \\
\hline Değişken & Katsayı & t & $\mathbf{p}$ & Katsayı & $t$ & $\mathbf{p}$ & Katsayı & $t$ & $\mathbf{p}$ \\
\hline lcrd & $\begin{array}{l}1.013 .836^{* * * *} \\
(.1909196)\end{array}$ & 5.31 & 0,000 & $\begin{array}{l}1.058342 * * * \\
(.1955259)\end{array}$ & 5.41 & 0,000 & $\begin{array}{l}1.311191 * * * \\
(.3984415)\end{array}$ & 3.29 & 0,006 \\
\hline income & $\begin{array}{l}.0000256 * * * \\
(6.09 \mathrm{e}-06)\end{array}$ & 4.21 & 0,001 & $\begin{array}{l}.0000238 * * * \\
(5.51 \mathrm{e}-06)\end{array}$ & 4.32 & 0,001 & $\begin{array}{l}.0000273 * * \\
(.0000109)\end{array}$ & 2.51 & 0,026 \\
\hline edu & $\begin{array}{l}0.041060 * * * \\
(.0082599)\end{array}$ & 4.97 & 0,000 & $\begin{array}{l}.0527485 * * * \\
(.0077988)\end{array}$ & 6.76 & 0,000 & $\begin{array}{l}.0029346 \\
(.0186361)\end{array}$ & 0.16 & 0.877 \\
\hline age & $\begin{array}{l}0.084507 * * * \\
(0.0041254) \\
\end{array}$ & 20.48 & 0,000 & $\begin{array}{l}.0940963 * * * \\
(.0033951)\end{array}$ & 27.72 & 0,000 & $\begin{array}{l}.0345686 * * * \\
(.0099585)\end{array}$ & 3.47 & 0,004 \\
\hline SS & $\begin{array}{l}0.010725 * * * \\
(.0023217) \\
\end{array}$ & 4.62 & 0,000 & $\begin{array}{l}.0157043 * * * \\
(.0021036)\end{array}$ & 7.47 & 0,000 & $\begin{array}{l}-.0135782 * * * \\
(.004028)\end{array}$ & -3.37 & 0.005 \\
\hline sabit & $\begin{array}{l}6.434 .86 * * * \\
(.4446042)\end{array}$ & 14.47 & 0,000 & $\begin{array}{l}5.697373 * * * \\
(.5312438)\end{array}$ & 10.72 & 0,000 & $\begin{array}{l}8.398921 * * * \\
(.4448784)\end{array}$ & 18.88 & 0,000 \\
\hline $\mathrm{F}$ & 154,47 & & & $\mathrm{~F}$ & 129,47 & & $\mathrm{~F}$ & 53,66 & \\
\hline $\mathrm{p}$ & 0,000 & & & $\mathrm{p}$ & 0,000 & & $\mathrm{p}$ & 0,000 & \\
\hline
\end{tabular}

Tahminde dirençli standart hatalar kullanılmıştır. Parantez içindeki değerler standart hataları göstermektedir. *, **ve *** sırasıyla 0,10,0,05 ve 0,001 düzeyinde anlamlığl temsil eder. lkbsh: satın alma gücü paritesine göre hesaplanmış kişi başı toplam sağlık harcaması logaritması, dolar cinsinden, lgov: satın alma gücü paritesine göre hesaplanmış kişi başı toplam kamu sağlık harcaması logaritması, dolar cinsinden, loop: satın alma gücü paritesine göre hesaplanmış kişi başı toplam cepten sağlık harcaması logaritması, dolar cinsinden income: satın alma gücü paritesine göre toplam kişi başı gayri safi yurt içi hasıla tutarl, dolar cinsinden age: +65 yaş üzeri nüfusun toplam nüfus içindeki payl, ss: toplam sağlık harcaması içindeki kamu sağlık harcamalarının oranı, edu: beklenen okullaşma yılı

F testi zaman etki sınaması sonuçlarına göre, her üç modelde de zaman etkisinin olmadığ1 sonucuna ulaşılmıştır. Üç modelinde olasılık değerleri 0,05 ' in üzerinde hesaplanmıştır.

Yapılan model uyumu sinaması $F$ testine göre kronik solunum yolu hastalıklarının sağlık harcamaları üzerindeki etkisini inceleyen panel veri modelleri,yöntemde açıklanan 2 numaralı denklemdeki gibi tek yönlü birim etkiler içeren modeller olacaktır.

Model tahmin sonuçlarına geçmeden önce, modelde yer alan birim etkilerin bağımsız değişkenlerle korelasyonlu olup olmadığının sınaması gerçekleştirilmiştir. $\mathrm{Bu}$ sınamanın gerçekleştirilme nedeni tahmin aşamasında kullanılacak olan tahminciye karar vermektir. Modelde yer alan birim etkisi bağımsız değişkenlerle korelasyonlu ise tek yönlü birim etki içeren sabit etkiler modeli ve tahmincileri, korelasyonlu değil ise tek yönlü birim etki içeren tesadüfi etkiler modeli ve tahmincilerinin kullanılması sapmasız ve tutarlı sonuçlar elde etmek için doğru olacaktır. Yapılan Huasman sınaması sonucunda her 3 modelin de test sonucu 0,05 düzeyinde anlamlı bulunduğundan, tahmin aşamasında tesadüfi etkiler yerine sabit etkiler modeli kullanılmıştır.

Birim etki içeren tek yönlü sabit etkiler modeli tahminicisi olarak Grup İçi Tahmiciyöntemi kullanılmıştır. Kronik solunum yolu hastalıklarının sağlık harcamaları üzerindeki etkisini tahmin etmek 
için oluşturulan modellerin varsayım sınamaları gerçekleştirilmiştir. Modelde, heteroskedasite varsayımı için Wald Testi, birimler arası korelasyon sınaması için Pesaran CD testi ve son olarak otokorelasyon sınaması için LBI ve Durbin Watson (DW) testleri kullanılmıştır. Yapılan Wald Testi, Pesaran CD testi ve LBI-DW testi sınamalarına göre üç modelde de her üç varsayımdan da sapma vardır. $\mathrm{Bu}$ nedenle nihai model tahmin sonuçları DriscollKraay dirençli standart hatalar tahmincisiyle tahmin edilmiştir. Yapılan tahmin sonuçları Tablo 4'teki gibidir.

Değişen varyans, birimler arası korelasyon ve otokorelasyon sorununu dikkate alınarak yapılan tahmin sonuçlarına göre sağlık harcamalarının belirleyicileri üzerine ortaya koyulan $\mathrm{Xu}$ ve arkadaşlarının (2011) modelinin, kronik solunum yolu hastalıkları prevelans değeri ile birlikte genişletilmiş hali olan kronik solunum yolu hastalıklarının logaritmasının, kişi başı toplam sağlık harcamasının logaritması üzerindeki etkisini inceleyen Model-1 sonuçlarına göre tüm değişkenlerle toplam kişi başı sağlık harcaması arasında pozitif yönlü bir ilişki vardır. Kronik solunum yolu hastalıkları prevelans değerinin logaritması ile kişi başı toplam reel sağlık harcamasının logaritması arasında \%1 düzeyinde istatistiksel olarak anlamlı pozitif ilişki bulunmuştur. Buna göre kronik solunum yolu hastalıkları prevelansında meydana gelen \%1 lik bir artış, kişi başına düşen toplam sağlık harcamasını \%1,03 oranında arttırmaktadır. Kronik solunum yolu hastalıklarının, kişi başı toplam kamu sağlık harcaması üzerindeki etkisini inceleyen Model-2 sonuçlarına göre tüm değişkenlerle sağlık harcaması arasında pozitif yönlü bir ilişki vardır. Kronik solunum yolu hastalıkları prevelans değerinin logaritması ile kişi başı toplam kamu sağlık harcamasının logaritması arasında \%1 düzeyinde istatistiksel olarak anlamlı pozitif ilişki bulunmuştur. Buna göre kronik solunum yolu hastalıkları prevelansında meydana gelen \% 1'lik bir artış, kişi başına düşen toplam kamu sağlık harcamasını \% $\%$,05 oranında arttırmaktadır.Kronik solunum yolu hastalıklarının, kişi başı toplam cepten sağlık harcaması üzerindeki etkisini inceleyen Model-3 sonuçlarına göre hastalıkların prevelans değerinin logaritması ile kişi başı toplam cepten sağlık harcamasının logaritması arasında istatistiksel olarak \%1 düzeyinde anlamlı bir ilişki tespit edilmiştir. Buna göre kronik solunum yolu hastalıklarının artması, cepten yapılan sağlık harcamalarının yükselmesine neden olmaktadır. Katsayı pozitif işaretlidir.Kronik solunum yolu hastalıkları prevalansının farklı sağlık harcaması göstergeleri üzerindeki etkisini inceleyen Model-1, Model-2 ve Model-3 sonuçları kıyaslandığında, hastalığın prevelansının logaritmasının satın alma gücü paritesine göre kişi başı toplam sağlık harcaması miktarının logaritması üzerinde, kişi başı toplam kamu sağlık harcaması miktarının logatritması, ve kişi başı toplam cepten sağlık harcamasının logatirtması üzerinde istatistiksel olarak anlamlı ve pozitif etkisinin olduğu sonucuna ulaşılmıştır.

\section{TARTIŞMA}

Bireyin veya toplumun sağlığı ile ekonomik düzey arasındaki ilişki, sağlık ekonomisinin çalışma alanlarından birisidir. Sağlık ve ekonomi arasındaki ilişkiyi inceleyen çalışmalarda, sağlık durumu göstergesi olarak en sık kullanılan değişkenler, doğumda beklenen yaşam süresi ve bebek ölüm hızıdır. ${ }^{(25)}$ Ampirik çalışmalardan elde edilen bulgular, genellikle sağlik durumu ile ekonomik düzey arasında güçlü bir pozitif ilişki olduğunu ortaya koymaktadır. Sağlık durumu daha iyi olan ülkelerin, sağl1k durumu daha kötü olan ülkelerden daha yüksek gelirleri vardır. ${ }^{(26)}$ Ayrıca, zengin ülkelerde yaşam beklentisinin, daha fakir ülkelere göre daha yüksek ve bebek ölümlerinin daha düşük olduğu doğrudur. (27)

Hastalıkların, ekonomik etkileri üzerine olan çalışmalar ise önceleri daha çok HIV/AIDS gibi bulaşıcı hastalıkların etkisine odaklanmış iken, son yıllarda toplumların hastalık yüklerinin değişmesi sonucu yapılan çalışmalarda kanser, obezite, kronik solunum yolu hastalıkları, kardiyovasküler hastalıklar gibi bulaşıcı olmayan hastalıkları inceleyen çalışmalar artmaya başlamıştır. Yapılan çalışmalarda, genellikle hastalıkların olumsuz ekonomik etkileri bulgulanmıştır. Örneğin Tandon, 2005 yılında Asya ve Pasifik Bölgesi'nde HIV / AIDS'in makroekonomik etkisi solow büyüme modelini kullanarak panel regresyon model ile incemiş ve artan HIV prevalansının sağlık sermayesi ve ekonomik büyüme üzerindeki olumsuz etkisi olduğunu tespit etmiştir. ${ }^{(28)}$ Benzer şekilde Cuddington, 1993 yılındaki çalışmasında AIDS'in önünün kesilmez ise 2010 yılında Tanzanya'nın GSYİH'nı ciddi bir oranda azaltabileceğini ve kişi başına düşen gelir seviyelerinin düşmesine neden olacağını hesaplamıştır. ${ }^{(29)}$ Cuddington ve Hancock, AIDS'in Malavi ekonomisinin büyümesi üzerindeki etkisinin değerlendirilmesi amacıyla yaptıkları çalışmalarında, genişletilmiş solow büyüme modeli yardımı ile AIDS'in ekonomik olarak olumsuz etkilerinin olduğu sonucuna ulaşmışlardır. ${ }^{(30)}$

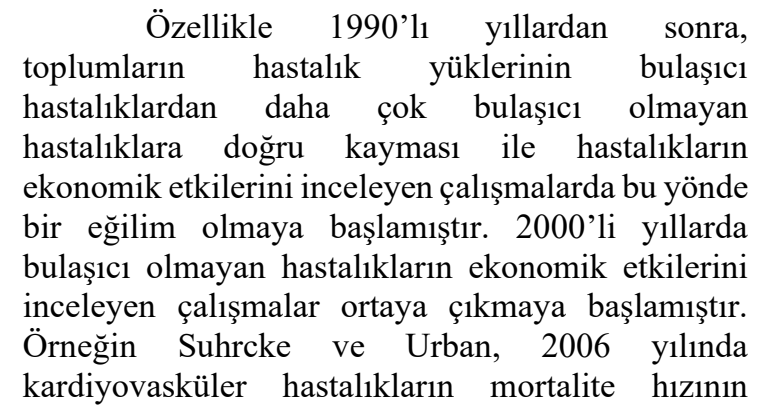


ekonomik büyüme açısından etkisini inceledikleri çalışmalarında, kardiyovasküler hastalıkların mortalitesinin ekonomik büyüme üzerindeki etkisini gelir gruplarına göre araştırmışlardır. Kurmuş oldukları dinamik panel veri modeli sonucuna göre düşük ve orta gelirli gruplarda, bu hastalığın ekonomik büyüme üzerinde önemli bir etkisi olmamasına karşın, yüksek gelir gruplarında, büyüme oranlarına güçlü bir olumsuz etkisi olduğunu bulgulamışlardır. ${ }^{(31)}$ Abegunde ve Stanciole ise, 2006 yılında seçilmiş ülkelerde panel veri yardımı ile kardiyovasküler hastalıkları da içeren kronik hastalıklardan kaynaklanan ölümlerin işgücü ve tasarruflar üzerindeki etkisinin bir sonucu olarak ulusal gelirde kayda değer miktarda kayıp olacağını tespit etmişlerdir. ${ }^{(32)}$ Liu ve arkadaşları ise, İngiltere'dekoroner kalp hastalığının doğrudan maliyetlerini prevelansa dayalı yaklaşım ile dolaylı maliyetlerini ise ayrık maliyet yaklaşımıyla tahmin etmişlerdir. Yaptıkları analiz sonucunda, koroner kalp hastalığının 1999'da İngiltere'de maliyetinin 1.73 milyar sterlin verimlilik kayb1 \% 24,9 olduğunu tespit etmişlerdir. (22) Schmid 2015 y1lında, 2003 yılından sonra Almanya'da kardiyovasküler hastalıkların tedavi edilmesinin doğrudan tıbbi maliyetlerine ilişkin bireysel kanıtları hasta bazında sistematik olarak derleyerek, bu hastalıkların Alman sağllk sistemi üzerinde yüksek mali etkiye sahip olduğu sonucuna ulaşmıştır. ${ }^{(23)}$ Çalışmamızda da, literatürde yapılan çalışmaları destekler sonuçlar elde edilmiştir. İncelenen dönemde OECD ülkelerinde kronik solunum yolu harcamaları ile sağlık harcamaları arasında anlamlı pozitif yönlü ilişkiler bulgulanmıştır.

\section{SONUC}

Bulaşıcı olmayan hastalıkların (BOH) yükü, küresel düzeyde kabul edilemez şekilde yüksektir. Bu hastalıklar, dünya çapında önde gelen ölüm ve hastalık yükü nedenleridir. Ayrıca bu hastalıkların sosyal ve ekonomik etkileri vardır. Bu hastalıklar nedeniyle insanlar yoksulluğa düşmekte, işgücü verimliliği azaltmakta ve ekonomik refah tehdit edilmektedir. Bulaşıcı olmayan hastalıklar, aynı zamanda muazzam firsat eşitsizlikleri yaratarak, zenginler ve yoksullar arasındaki farkın açılmasına da neden olmaktadır. Tüm ülkelerde, en fakir ve en savunmasız nüfus, en fazla risk altında olan ve bulaşıcı olmayan hastalıkları tespit etmek ve tedavi etmek için ihtiyaç duydukları hizmetlere erişme olasılığı en düşük olan nüfustur. Ayrıca bulaşıc1 olmayan hastalıklar, gerek gelişmiş, gerekse de gelişmekte olan ülkelerde mali açıdan risk oluşturmakta ve sağlık sistemlerinin finansal açıdan devamlılığını ve etkinliğini tehdit etmektedirler. Ekonomik açıdan kaynakları daha sınırlı olan düşük ve orta gelir düzeyindeki ülkelerde ise bu hastalıkların toplumda artması daha yüksek bir finansal sorun yaratmakta ve bu hastalıklar nedeniyle bakım ve tedavi masraflar katastrofik sağlık harcamalarına neden olmaktadır.

$\mathrm{Bu}$ hastalıklar, ekonomik ve sosyal kalkınmayı olumsuz etkiler ve ayrıca ülke ve bölgeler arasında kaynakların eşitsizliğini nedeniyle firsat eşitsizliklerinin derinleşmesine sebep olur. $\mathrm{Bu}$ yönüyle bir halk sağllğ 1 sorunu olarak da görülmektedirler. Bu riskleri ve tehditleri ortadan kaldırmak için küresel, bölgesel ve ulusal düzeylerde ortak çalışmalara ve kararlılıklara ihtiyaç duyulmaktadır. Bilimsel çalışmalar, özellikle risk unsurlarını azaltacak eylem planları ile bulaşıcı olmayan hastalık yüklerinin önüne geçilebileceğini, hastalıkları önleme ve kontrol müdahalelerinin yanı sira maliyet etkin koruyucu önlemlerle finansal risklerin de büyük ölçüde azaltılabileceğini göstermektedir. $\mathrm{Bu}$ noktada sağlık ekonomisi disiplininin önemli katkıları olacaktır. Bu kapsamda bulaşıcı olmayan hastalıkları önleme, bulaşıcı olmayan hastalıklar ve risk faktörleriyle ilgili sağlık sistemi cevabını güçlendirilme ve bulaşıcı olmayan hastalıkların trendlerini ve belirleyicilerini izleyerek, önleme ve kontrol konusunda kaydedilen ilerlemeyi değerlendirmeye yönelik çalışmaların yapılması önemlidir.

\section{KAYNAKLAR}

1. Wang Q, Brenner S, Kalmus O, Banda HT, Allegri MD. The Economic Burden of Chronic Noncommunicable Diseases in Rural Malawi:An Observational Study. BMC Health Services Research 2016; 16: 1-9.

2. Alwan A, Armstrong T, Bettcher D, et al. Global status report on on noncommunicable diseases 2010. Genevre: WHO. 2011. p.9-16.

3. Lozano R, Naghavi M, Kyle Foreman, et al. Global and Regional Mortality from 235 Causes of Death for 20 Age Groups in 1990 and 2010: A Systematic Analysis for the Global Burden of Disease Study 2010. The Lancet 2012; 380(9859): 2095-2128.

4. Türkiye İstatistik Kurumu. (2012). Ölüm Nedeni İstatistikleri. Available at: http://www.tuik.gov.tr/PreTablo.do?alt id=108 3 Erişim tarihi 14 Eylül 2020. (Accessed September 14, 2020.)

5. Ministry of Health and World Health Organization European Office. - Multistakeholder Turkey NCD Action Plan 20172025. Ankara: TR Ministry of Health. 2017. p.12.

6. Suhrcke M, Urban D. Are Cardiovascular Diseases Bad for Economic Growth? Cesifo Workıng Paper No. 1845. 2006. 
7. Torun P, Kutlar A. Türkiye'de Kanserin Ekonomik Maliyetleri: Bir Hesaplanabilir Genel Denge Modeli Yaklaşımı. Hacettepe Sağlık İdaresi Dergisi 2018;21 (1): 31-39.

8. Roser M., Ritchie H. Burden of disease. Our World in Data. Advance online publication. Available at: https://ourworldindata.org/burden-of-disease Erişim tarihi 10 Eylül 2020. (Accessed September 10, 2020.)

9. Greene WH. Econometric Analysis. New York: Pearson Education Publication. 2012. p.283339.

10. Yerdelen Tataoğlu F. Panel Veri Analizi. İstanbul: Beta. 2018.p.7.

11. Wooldridge JM. Econometric Analysis of Cross Section and Panel Data. London: The MIT Press. 2002.p. 3-11.

12. Xu K, Saksena P, Holly A. The Determinants of Health Expenditure. Geneva: World Health Organization.2011. p.1-28.

13. Newhouse J. Medical Care Expenditure: A Cross National Survey. Journal of Human Resources 1977;12: 115-125.

14. Gerdtham U, Jonsson C. An Econometric Analysis of Health Care Expenditure, A Cross Section Study of OECD Countries. Journal of Health Economics 1992;11: 63-84.

15. Hitiris T, Posnett J. The Determinants and the Effects of Health Expenditure in Developed Countries. Journal of Health Economics 1992; 11: 173-181.

16. Getzen T. Forecasting Health Expenditures: Short, Medium and Long Term. Journal of Health Care Finance 2000;26: 56-72.

17. Baltagi BH, Moscone F. Health Care Expenditure and Income in the OECD Reconsidered: Evidence from Panel Data. Economic Modelling 2000;27(4): 804-811.

18. Mutlu A, Işık A. Sağlık Ekonomisine Giriş. Bursa: Ekin Publishing.2012. p.50-70.

19. Arun Ö. Yaşlı Bireyin Türkiye Serüveni: Kaliteli Yaşlanma İmkânı Üzerine Senaryolar. Gaziantep Üniversitesi Sosyal Bilimler Dergisi 2008;7(2): 313-330.

20. Fujino S. Health economics in Japan: Prospects for the Future. In G. Smith (Eds), Health
Economics: Prospects for the Future. Croom Helm. 1987. p.85-91

21. Seshamani M, Gray A. The Impact of Aging on Expenditures in the National Health Service. Age and Aging 2002;31: 287-294.

22. Liu J, Maniadakis N, Gray A, Rayner M. The Economic Burden of Coronary Heart Disease in the UK. Heart 2002; 88(6): 597-603.

23. Schmid T. Costs of Treating Cardiovascular Events in Germany: A Systematic Literature Review. Health Economics Reviews 2015; 5(1): 27.

24. Vandenberghe D, Albrecht J. The Financial Burden of Non-Communicable Diseases in the European Union: A Systematic Review. European Journal of Public Health 2019;73.

25. Strauss J, Thomas D. Health overthe life course. In T. Schultz. \& J. Strauss (Eds), Handbook of development economics. California: University of California. 2008.p.1-3.

26. Bloom DE, Kuhn M, Prettner K. Health and economic growth. IZA Institude of Labor Economics Paper Series 11939. 2018. P.2-26.

27. Audibert M, Motel PC, Drabo A. Global Burden of Disease and Economic Growth. Sciences de l'Homme et de la Société 2012; (12): 1-35.

28. Tandon A. Macroeconomic Impact of HIV/AIDS in the Asian and Pasific Region. ERD Workin Paper Series 2005:75; 1-29.

29. Cuddington JT. Modeling The Macroeconomic Effects of AIDS, With an Application to Tanzania (English). The World Bank. 1993. P.173-89.

30. Cuddington J, Hancock J. Assessing the Impact of AIDS on the Growth Path of the Malawian Economy. Journal of Development Economics 1994; 43(2): 363-638.

31. Suhrcke M, Urban D. Are Cardiovascular Diseases Bad for Economic Growth? Health Economics 2010;19: 1478-1496.

32. Abegunde D, Stanciole A. An estimation of the economic impact of chronic noncommunicable diseases in seleceted countries: World Health Organization Working Paper 2006. p.1-21. 